\title{
Introduction
}

\section{Ryo Shimanami}

Since it first took shape in England in the 17th century, the patent system has consistently continued to enhance its function and effects. Yet there has been no era other than today where the significance of the patent system has been questioned and calls have been made for reform. Pathological phenomena, such as the sharp increase in the number of patent applications, the decrease in the quality of patent rights, the increase in the cost of patent infringement lawsuits among other phenomena, are now common and serious issues in many countries and regions. Papers and publications with provocative titles referring, for example, to the crisis or failure of the patent system, have become too numerous to count.

This book intends to analyze different perspectives on the turning point now faced by today's patent system under the current period of reform and different visions for its future, based on its status in Japan, the U.S., Europe, India, Brazil and China, where the level of acceptance of the patent system varies, and by applying two theories, which have different approaches: jurisprudence and economics.

Part I presents the arguments of a Japanese jurist and economist and an American scholar with profound knowledge of the law and economics on the current status and vision of the patent system. The following points will be examined in this chapter: whether the patent act provides uniform norms for all technologies and disputes, and how far the patent right retains the characteristics of a traditional exclusive right.

First, Chapter 1 clarifies from a jurisprudence perspective that the uniformity and versatility of the norms that were originally a part of the patent system have been lost today and there is often a tendency to apply a temporary adjustment of interests. With regard to issues such as infringement under the doctrine of equivalents, indirect infringement, exhaustion of rights, inventions by employees, etc., the transition in the characteristics of applicable norms from rules that are formal and adequately stable to standards that are substantive and highly appropriate is described. In addition, with the increased use of the method for the substantial balancing of interests to which the aforementioned standards are applied, 
the standards for the balancing of interests become more important in the future. The author thus examines the standards by returning to the very beginning point, justification theory, and the consideration of the reasons why the patent system exists. On this basis, the author examines the standards for categorizing the various types of norms that are included in the patent act into rules and standards; and raises warnings about the current situation of the Japanese Patent Act where the patent act is losing its coherence as a single law as a result of the excessive use of standards. From the phenomenon in the U.S. where the U.S. Supreme Court denied the formal interpretation of the patent act provided by the U.S. Court of Appeals for the Federal Circuit (CAFC) and demanded a more flexible interpretation, it can be seen that, in fact, this standardization of the patent act is a cross-border issue.

Chapter 2 examines in a demonstrative way, from an economic perspective, what effects the reinforcement of patent rights in Japan, in other words, the amendment of the legal system in a pro-patent direction, has had on trends in innovation in Japanese companies (for instance, corporate activities, such as research and development investment, patent application, licensing, etc.). As a result of the examination, the following matters are noted: the pro-patent policy did not cause significant changes in the innovation tendencies of Japanese companies. However, it had a greater impact on high-tech industries, including the electronics and pharmaceutical industries, than on other industries, while the degree and content of the impact are different when comparing the electronics industry and pharmaceutical industry. There are previous research studies in Europe and the U.S. with respect to the effects of pro-patent policies. Their results have shown that the impact on company activities varies by country or industry field. If so, there should be reasons for the recent tendency to become mainstream in the supreme courts of Japan and the U.S. where uniform rules are not applied to all disputes, but are adjusted subtly in each case by applying standards.

Moreover, in Chapter 3 it is shown that the current status of many industries other than the pharmaceutical industry reveals how the existence of the patent right has been ignored. The author indicates that situations where a patented invention is used by others without obtaining approval from the patent right holders are rampant in practical business practices. This loss of the patent right function reveals a significant difference from other cases where it is extremely rare that tangible objects (in particular, land) are used by others without obtaining the approval of the property right holders. On this basis, the author clarifies that unlike the property right system, the operation of the patent system, where rigid right treatment is not implemented prior to the use of an object, has a certain 
reasonability. The author then defines a concept of an efficient patent license market located between the extremes - the rigid protection of rights as shown in the cases of property rights and the ignorance of rights - and makes concrete suggestions along with the concept, such as the disclosure of applications at an early stage, mandatory disclosure of the license term, etc. Underlying this concept is an attempt to transform the patent right from a traditional exclusive right to the right to claim value and to demand the conversion of basic characteristics of the patent system to give invention incentives by granting exclusive rights.

In Part II, issues related to patent systems in Europe, the U.S. and Japan and the path to resolving these issues are examined from the respective positions of Patent Office practitioners, jurists and economists. Japan, the U.S. and Europe are advanced countries and regions of economic development and have long histories with respect to the use of the patent system when compared with other countries. However, the trend towards reinforcing patent rights (pro-patent policy) that was adopted in these three countries and regions starting in 1980 caused pathological phenomena, such as the increase in the number of patent applications over the last quarter century and has had the adverse effect of restricting innovation in society overall. The crisis of the patent system in Japan, the U.S. and Europe may lead to a world-wide crisis in the patent system if appropriate measures are not taken now.

In Chapter 4, the current status of patent systems in Europe, four scenarios for the future and countermeasures for issues are examined from the point of EPO examiners and others. In this chapter, the strides in cross-border harmonization between patent systems for which Europe is a world leader are introduced. The author then describes the four scenarios that the European patent system may face: (i) a world where patents will function increasingly as financial means for large-scale companies and the patent system will collapse; (ii) a world where multiple regional patent systems coexist; (iii) a world where the social trust in patent systems will be lost and other ways to provide R\&D incentives are explored; and (iv) a world where the patent system itself transforms along with the rapid progress in technology. In this chapter, specific strategies are also examined where the patent system stands against the issue of the sharp increase in the number of patent applications (so-called "global patent warning"), such as strategies increasing the level of progress, etc., in the four aforementioned scenarios. In conclusion, the author issues a strong warning that there is no option to take no measures now against issues that the patent system faces regardless of the scenario that the patent system will face in the future.

In Chapter 5, an American jurist describes one vision of the U.S. Patent 
Act. The author indicates here how the U.S. Federal Circuit has proactively embodied abstract language in the patent act since its foundation in 1982 and developed its own theory that is different from other areas of the law; on the other hand, the U.S. Supreme Court, which is superior to the Federal Circuit, has limited excessive action by the Federal Circuit and strived to maintain homogeneity between the patent act and other areas of the law. Because of industries that are strong lobbyists to the patent system, such as pharmaceutical, biotech and IT companies, this chapter also reveals the recent state of the patent act repeating inconsistent amendments and their influences on patent practices, including the projections of the ripple effect that may arise from the Patent Reform Act of 2011, which incorporates the shift from the first-to-invent system to the first-tofile system. This analysis comes from the institutional theories that have been developed in recent years in the U.S., and it can be recognized as an attempt to question which institution (companies or nation; judiciary branch, legislative branch or administrative branch of the government; the Supreme Court or the Federal Circuit) should assume the role of building and operating the patent system.

Moreover, in Chapter 6, from the standpoints of a former examiner of the Japan Patent Office and an economist, the author discusses the behavior of Japanese companies in obtaining patents and the method to resolve the issue of slower examinations in the JPO, which has arisen due to this behavior. According to the discussion, supported by a corporate culture that has a strong desire to improve technology as well as to partake in copycat behavior, the number of patent applications per R\&D expenditure or for each researcher for Japanese companies is significantly higher than for companies in other countries. Due to the behavior of these companies in obtaining patents and shortening the period of demand for examination since 2001, the slowing down of examinations by the Patent Office in Japan has become a more serious problem than in other countries. This chapter demonstrates these phenomena in conformity with the data and proposes institutional reforms as measures to overcome them, such as diversifying the length of the period of demand for examination, which is currently a uniform period, restricting the exercise of the right to seek an injunction, setting a higher bar for inventive steps, among other changes.

In Part III, current status and vision of patent systems are discussed from the perspective of economically-developing countries, such as India, Brazil and China. These three countries are members of the so-called BRICS. All of these countries have extensive national land and large populations, and are rich in national resources, including coal, iron ore and natural gas. They have achieved rapid economic development over the last ten years thanks to their rich human and material resources without 
relying on intellectual property. At the same time, they are also facing a growing gap between rich and poor and difficulties in national unification due to their multiethnic populations. With regard to the patent system that was formulated by the economically-advanced countries and made globally dominant or imposed by international treaties, how does it function in BRICS and what issues does it face?

In Chapter 7, India is examined first, a country which has achieved rapid economic development, mainly in the IT industry, since the start of this century. India has operated a patent system for more than a century since it was imposed by the British. According to this chapter, there has always been an attempt in India to balance conflicting goals: economic development, by strengthening patent monopolies, and the realization of the need to allow people access to patented products by attenuating their strength. With regard to technologies that have a significant impact on people's lives, such as pharmaceutical products, computer programs, traditional knowledge, etc., protection by patent has been denied from the beginning, the bar for obtaining patent has been raised, and efforts have been taken to limit the effectiveness of the right. One of the main themes in this chapter relates to how long India will retain treatments that vary by technology field or industrial field under the TRIPS Agreement, which has a "one size fits all" philosophy. The current state of India is a worthy example not only for other BRICS countries, but also for patent-advanced countries that face various kinds of problems.

In Chapter 8 the problems and perspectives of Brazil are discussed. This country had provisions to protect property rights of inventors in its first Constitution (1824) after its foundation and established a patent act very early in 1830. As a patent-advanced country, Brazil, which was one of first allied nations of the Treaty of Paris, had a patent system that remained virtually asleep from the perspective of the protection of domestic industries after World War II. However, since the 1990s, the acknowledgement and use of the patent system have been spreading rapidly in order for the country to become a member of WTO and to import foreign capital. This chapter depicts the Brazilian patent system analytically as it strides to open a new way for bio-technology inventions to obtain patents along with its restrictions on patent monopolies for inventions that relate to public health, such as AIDS medicines, by exercising compulsory licenses. How is the balance found between the development of domestic industries by the introduction of foreign technologies and the protection of public health under the impact of globalization? The approaches in Brazil will serve as a forecast for future patent systems in the world.

Chapter 9 discusses China, whose first patent act was enacted only a quarter of a century ago in 1985. China not only has a short history of 
operating a patent act when compared with the other countries and regions discussed in this book, but it also has the characteristic of introducing a market economy progressively while maintaining a communist government. Under this government and economic system, the patent right had poor characteristics as private property at first; however, it gained an outline that substantially conforms to the systems of other foreign countries by means of legal amendments in 2001 and 2009 in order for the country to become a member of WTO. However, in actual operation, it is impossible to say that patent rights are sufficiently protected, while industrial development that is led by protection has been seen. Therefore, the Chinese government set the goal of accomplishing the completion of the intellectual property system by 2020 in its Outline of the National Intellectual Property Strategy issued in 2008. The Outline emphasizes an instrumentalism-like idea, which is different from the aforementioned cases in India and Brazil and positions the patent system solely as a means for industrial development. This chapter portrays a major power where the patent system is still under development in terms of the balance between strengthening the execution of patent rights and preventing the abuse of rights and in terms of how it attempts to respond to today's issues, such as Patent Thickets, technical standards, and other concerns.

It has been 20 years since the Institute of Intellectual Property was established based on the model of the Max Planck Institute in Munich. This book was planned in commemoration of the 20th anniversary and the Japanese version was released in 2009. Thanks to the high level of interest in Japan, this English version is also being released. As is always the case with this type of book under joint authorship by international authors, it is particularly difficult to publish without the support of many people. It is my wish to see the international development of the patent system. I would also like to express my deepest gratitude to the authors, the publisher, and to all of the people who supported this project. 